\title{
THE SCENARIO OF SOFTWARE ASSET MANAGEMENT (SAM) IN LARGE AND MIDSIZE COMPANIES
}

\author{
Ana Márcia Quitério Varela \\ Universidade Federal Fluminense, Brazil \\ E-mail: avarela33@gmail.com \\ Mirian Picinini Méxas \\ Universidade Federal Fluminense, Brazil \\ E-mail:mirian_mexas@vm.uff.br \\ Geisa Meirelles Drumond \\ Universidade Federal Fluminense, Brazil \\ E-mail: meirellesdrumond@gmail.com
}

Submission: 10/09/2017 Accept: 06/03/2018

\section{ABSTRACT}

The implementation of processes and tools of Software Asset Management (SAM) has become an action agenda for Information Technology (IT) managers. Then this study aims to investigate the scenario for the implementation of SAM in large and midsize companies of Rio de Janeiro, Brazil. As methodology, a literature review was performed which founded the creation of an online questionnaire applied to 53 Chief Information Officers (CIOs). Based on the result of this research, it was possible to identify the knowledge of managers pertinent to the concept of SAM, and the fact that the majority of the investigated companies are in stages 1 and 2 of the development of the tiers of SAM proposed by the ISO / IEC 19770 standard. As contribution, it is expected to elucidate the recognition of SAM as a relevant factor to be used in the IT area, aiming at the search for solutions that increase productivity and optimize the costs and investments in companies.

Keywords: information technology; IT management; software assets management 
DOI: 10.14807/ijmp.v9i2.730

\section{INTRODUCTION}

Information Technology (IT) is intrinsic part of the business of the companies, as well as an essential support to the operation of contemporary organizations (BOWEN; CHEUNG; ROHDE, 2007, FERNANDES; ABREU, 2008). Notwithstanding the perception of the aggregate value of IT to business, the decisions and management of IT resources become even more complex with the fast and constant technological advancements, leading to flaws in the management and definition of acquisitions (MCAFEE, 2004).

This sensitive relationship between the investment in IT and its impacts on business has been promoting the adoption of processes and management tools to orientate the decisions of the IT executives. It is in this context that the aspects of IT Management (ITM) become inserted in the agenda of the executives, as a resource for managing, qualifying and guarantying that the investments in technology are effectively in agreement, and promoting positive results for the business of the company (HAES; GREMBERGEN, 2005).

In this regard, the implementation of diverse IT processes - such as configuration, distribution and management of changes - depends on whether the company has accurate knowledge of its IT assets, in special, software assets. Nevertheless, the efficacy of a company may be seriously compromised when the organization does not have knowledge of the software assets it has, where they are located, how they were configured and how they are used, because the company may be paying too much to be granted or renew software licenses, or yet, to license them improperly.

Thus, the difficulty in managing software assets in agreement with the contractual rules established by the supplier has become a challenge to IT management. On the other hand, the software suppliers are intensifying their audit activities to confirm the license numbers for their clients. Besides agreement aspects, the lack of software asset management can result in significant and unexpected costs.

There are solutions to the automation of the management of assets in the market, but just the use of this type of tool does not accomplish or guarantee the implementation of all the processes that deal with software asset management. Thus, identifying, managing, optimizing and guarantying the compliance of software 
assets in the companies are factors that impel the companies to implement the process of software asset management.

In this context, the objective of this research is to investigate the scenario of implementation of software asset management in large and midsize companies of Rio de Janeiro, Brazil, by observing conditioning aspects that motivate and impact its implementation.

It is expected, with this study, to elucidate the recognition of software assets and offer information about its management through bibliographic review and investigation and analysis of the scenario of the implementation of software asset management in the researched companies.

\section{THEORIC FUNDAMENTATION}

This section emphasizes concepts and relevant aspects of Software Asset Management.

\subsection{Software Asset Management}

Initially, resorting to accounting, asset is a term used for expressing the possessions, valuables, receivables, rights and the like, which in a determined moment constitute the patrimony of a natural or legal person and which are evaluated by their costs (FULGENCIO, 2007).

In general terms, an asset defines something valuable that the company owns and that is associated with risks and benefits. Within the scope of IT, the assets cannot be limited to informatics equipment and software installed in the environment under the responsibility of IT management. The ABNT NBR ISO/IEC 27002 standard - Code of Practice for Information Security Management - defines asset as "anything that has value to the organization" and it can be represented as information assets, software assets, physical assets, services, people and intangible assets (ABNT, 2005).

According to Fernandes and Abreu (2008), the IT assets refer to the whole IT infrastructure, and comprehend computers, servers, storage devices, applications and support software, among others. Therefore, it is observed that IT assets comprehend hardware and software.

Wang et al. (2015) concluded that the IT assets do not impact the development of the companies directly. On the other hand, the capacity of 
INDEPENDENT JOURNAL OF MANAGEMENT \& PRODUCTION (IJM\&P)

http://www.ijmp.jor.br

v. 9, n. 2, April - June 2018

ISSN: 2236-269X

DOI: 10.14807/ijmp.v9i2.730

management of these assets, in an interactive and moderate way through environmental dynamics, is a strategic resource that can improve the competitive advantage and development of the company directly.

The IT Asset Management (ITAM) implicates the collection of inventory, financial and contractual data to manage IT assets during all its lifecycle. Software Asset Management (SAM) and Hardware Asset Management (HAM) are parts of the broadest discipline of ITAM.

In this context, the software assets of a company are formed by all the software systems that support the accomplishment of their organizational objectives. The term "software asset" is constituted by the right to use some specific software, which must be documented in software contracts, license documentation and receipts (ABES, 2014).

Although it is not described in details, the definition of ITIL (Information Technology Infrastructure Library) for SAM is "all of the infrastructure and processes necessary for the effective management, control, and protection of the software assets within an organization throughout all stages of their lifecycle", according to ABNT NBR ISO/IEC 19770 standard (ABNT, 2012).

Users, IT professionals, IT executives, suppliers, IT support, infrastructure and safety services are software asset management clients (FERNANDES; ABREU, 2008). Thus, the organizations need a strong process of software asset management. The International Organization for Standardization (ISO) and the International Electrotechnical Commission (IEC) defined the ISO/IEC 19770 standard as the one that establishes a base line for an integrated set of the processes of SAM, aligned with the management of services of ITIL library.

The ISO/IEC 19770 standard is composed by five main parts, being the first one, the ISO/IEC 19770-1 standard, the object of this study, because it is a structure of processes aimed at proving that SAM offers the adequate support to the management of IT assets to fulfill corporate requirements. Therefore, the main benefits of SAM must include: risk management; control of costs; competitive advantage.

The ISO/IEC 19770-1 standard (ABNT, 2012) defines four tiers that allow the implementation, assessment and recognition of the SAM requirements in stages. The scope details treated in each tier are described as follows: 
INDEPENDENT JOURNAL OF MANAGEMENT \& PRODUCTION (IJM\&P)

http://www.ijmp.jor.br

v. 9, n. 2, April - June 2018

ISSN: 2236-269X

DOI: 10.14807/ijmp.v9i2.730

Tier 1 - Reliable Database - it comprehends the first or preliminary stage, where the inventories are the basic source for an efficient process of software asset management. In this tier, the focus is to identify what is available, to know how to manage and supply the basis to demonstrate the compliance of the software ownership right. This is the Basic stage in the process of SAM.

Tier 2 - Pragmatic Management - it is the initial stage for Software Asset Management, per se. It starts by the recognition of the lack of asset data, extension risk, improvement opportunities and economy. Through the reliable database, constituted in Tier 1, quick wins are obtained, it means, immediate benefits with basic software asset management. In this tier, the establishment of rules, policies, responsibilities and definition of the competencies of SAM are comprehended.

Tier 3 - Operational Integration - it is based on the foundation of the two previous tiers, inserting integration processes with contract management, financial aspects through a security system for asset agreement, covering the acquiring, utilization and downloading phases of the software. In this phase, the result is the improvement of the efficiency and effectiveness of the process of software asset management. This is the Rationalized stage in the process of SAM.

Reaching Tier 4 stage - Complete Agreement - means achieving the ideal strategic stage, allowing the process of software asset management to support the strategic business objectives, bringing reduction of costs, operational cycle optimization, production increase and competitive innovation. It defines the concept of mechanisms that, once in operation, will allow the company to stay in compliance in a continuous and constant way, by reviewing the results of the implementation of the initial tiers. It is the Optimized stage in the process of SAM.

The standard still defines the objectives for each one of the activities or process areas, informing to which tier such objective is applied, the satisfaction requirements and possible results, aiming at certifying the maturity level of SAM, which can be attested when all the requirements of a tier are achieved, or yet, when all the objectives of a tier are achieved. It also recommends the continuous monitoring of these requirements and objectives to guarantee the maintenance of a maturity level that has already been reached.

The main required competences for the operation of software asset management were highlighted by Fernandes and Abreu (2008): Software contract 
management; Regulations of Property Ownership and Copyright; Audit techniques in software asset management; Knowledge of tools for software asset management.

The roles and responsibilities of SAM, according to the ISO/IEC 19770-1:2012 standard, are centered on the profiles owner/administrator (SAM owner) and SAM local administrator (local SAM owner). It is for the owner/ administrator to develop the SAM plan of an organization, by defining its objectives and guarantying the necessary resources to deliver the planned results. It is for the local administrators to manage SAM per se, it means, to document software assets and implement the SAM policies and procedures, including the management of suppliers and assessment of licensing necessities.

\section{RESEARCH STRATEGY}

Next, the adopted methodological procedures for the accomplishment of the research, which had the following stages to achieve their objectives, were presented:

$1^{\text {st }}$ Stage - The accomplishment of a cycle of bibliographic researches and literature review was the starting point for the determination of the adequate theoretical framework to understand the state of the art of this research, through bibliographic records. This phase was fundamental to determine the problem situation and the relevance of the research, confirming the choice of the theme.

$2^{\text {nd }}$ Stage - Identification, based on the literature, of the relevant aspects of the process of software asset management, which may be objects of verification in the practices of IT managers that aim at the objective of the research.

$3^{\text {rd }}$ Stage - Development of a quantitative questionnaire from the aspects identified in the $2^{\text {nd }}$ stage and from other elements and sources that could contribute to reaching the objectives, validating them through a previous application with three IT managers and scholars.

$4^{\text {th }}$ Stage - Mapping of the perceptions of the implementation of software asset management, through the application of a questionnaire, developed in the previous stage, to the IT managers in companies of Rio de Janeiro, which was distributed and answered online.

$5^{\text {th }}$ Stage - Analyses of the results and conclusion of the study in light of the objective of the research, emphasized in perspectives of future works.

In relation to the literature review, the ISO/IEC 19770 standard brought the central term of this research - software asset management. Besides the low 
INDEPENDENT JOURNAL OF MANAGEMENT \& PRODUCTION (IJM\&P)

http://www.ijmp.jor.br

v. 9, n. 2, April - June 2018

ISSN: 2236-269X

DOI: 10.14807/ijmp.v9i2.730

incidence of records found on the portal of periodicals of CAPES-- Coordenação de Aperfeiçoamento de Pessoal de Nível Superior --, only the Scopus and Web of Science database records were considered, due to the reliability and quality of their contents.

By refining the researches in the bases, the records obtained with the key words "ISO/IEC 19770", the combination of "software asset" and "management", "software" and "license agreement", besides the central term itself, were considered relevant to the theme, resulting in 73 distinct records. From these 73 initial articles, the diversity of research themes about software assets was observed, making a deeper investigation to identify studies related to the management and control of such assets necessary. Then, 11 articles that really corroborated the comprehension of the research theme, and that founded the questionnaire described in the $3^{\text {rd }}$ Stage, were selected.

The questionnaire was elaborated with closed questions, grouped in 2 blocks, being the first one about the profile of the company, with 8 (eight) questions. The second block with 12 (twelve) questions that aim at investigating the current scenario of the company in relation to software asset management.

Questions 9 to 20 were conceived to receive the following answers: 5 (Yes, automated), 4 (Yes), 3 (Do not know), 2 (Not yet (suggests future intention)), 1 (No).

As described in the $3^{\text {rd }}$ Stage, the elaborated questionnaire was legitimated through a pre-test applied to three members of the research group who were selected to assess the clarity, the number of questions and the average answering time. The pre-test result did not indicate the necessity of alteration in the format or number of questions.

Therefore, the questionnaire could be published on the virtual forum of the group - CIORJ (Chief Information Officer of Rio de Janeiro) - in Yahoo Groups, composed by 80 IT managers from large and midsize companies based in the city of Rio de Janeiro, being each manager a representative of a company.

\section{ANALYSIS OF RESULTS}

In this stage, the processing and analysis of the result of the research with the involved public is presented, by comparing it with the data found during the literary review. 
INDEPENDENT JOURNAL OF MANAGEMENT \& PRODUCTION (IJM\&P)

http://www.ijmp.jor.br

v. 9, n. 2, April - June 2018

ISSN: 2236-269X

DOI: 10.14807/ijmp.v9i2.730

The elaborated questionnaire applied in this research was available for answering for 20 days, between the dates 06.27.16 and 07.16.16, and was made with the support of the online research tool software Survey Monkey. The invitation to participate in the research was sent to 80 members of the CIORJ group, obtaining response from 53 of them, corresponding to a response rate of $62,25 \%$.

\subsection{Result of the Profile of the Companies}

The first block of answers sought to identify the profile of the companies in which the respondents act as IT managers, with descriptive and quantitative answers, related to legal nature, income, business segment, the number of employees and hardware assets, and still to the use of cloud computing and serve virtualization.

The first question of this block (Q1) aimed at mapping the legal nature of the companies, and it was observed that $90,57 \%$ are private companies, in which producing with the lower costs to generate profits is one of the main objectives; $9,43 \%$ are public companies. Therefore, the management of software assets used in the organization must promote efficient cost through the acquisition and maintenance of licensing, in a way to cooperate with such objective.

The following question, question 2 (Q2), intended to investigate the average annual income of the organizations. It was observed through the analysis of income that $7,55 \%$ are small and midsize companies, $11,32 \%$ are midsize-large companies and $81,13 \%$ are large companies, considering the criteria defined by the National Bank for Economic and Social Development (BNDES, 2010). Thus, the quantity, diversity and amount in software development tend to follow the size of the company, being it the interest for this issue.

The mapping of the economic activity segments was object of investigation in the third question (Q3). Approximately 30\% of the companies perform in the Industry, Trade and Services segment, being the answers 32,08\%, 26,42\%, 11,32\%, respectively. A significant number of $22,64 \%$ could not be identified, being classified in the category Another. The remaining companies perform in Education (3,77\%), Technology (1,89\%); and Telecommunications (1,89\%).

However, by this point it can be enlightened that the majority of the respondents work in large private companies of the 3 (three) main economic segments, thus, being a significant and expressive sample to analyze aspects of 
INDEPENDENT JOURNAL OF MANAGEMENT \& PRODUCTION (IJM\&P)

http://www.ijmp.jor.br

v. 9, n. 2, April - June 2018

ISSN: 2236-269X

DOI: 10.14807/ijmp.v9i2.730

software asset management, once the companies widely use software to perform their buying and production operations, confirming the adherence of the sample to the objectives of the research.

Yet in question 4 (Q4), the objective was to know the number of employees of the companies: 3,77\% with less than 100 employees; 13,21\% between 101 and 500; 15,09\% between 501 and 1000; and 67,92\% with more than 1000 employees. About the number of employees, the characteristics of the midsize and large companies could also be confirmed, being 67,92\% with more than 1000 employees.

Knowing the amount of computers and mobile devices was the next object of investigation in question 5 (Q5). The amount of desktop computers and laptops could be observed, and it was verified that 58,49\% of the respondents informed that there are more than 1000 pieces of equipment in their companies and $37,74 \%$ informed that there are between 100 and 1000 (18,87\% between 101 and 500, and 18,87\% between 501 and 1000); and 3,77\% with less than 100 pieces. The investigation on hardware assets justifies itself in the concept of software asset like the software/hardware combo, in this specific case, those programs related to the operational system.

Still in the ambit of hardware, the use of tablets and smartphones has become more and more common in the routine of the employees in the companies, independent of the position or role that they have. Thus, it is fundamental that the IT managers (Chief Information Officers - CIOs) face the challenge to manage these devices and mobile applications. In this ambit, the main challenges found by the ClOs are related to management, information security and software asset management, being the last one, the aspect that motivated question 6 (Q6).

It is observed the use of mobile corporate devices, considering tablets and smartphones, in which $41,51 \%$ of the respondents informed that in their companies there are between 101 e 500 devices and 32,08\% more than 1000. Also, 11,32\% have less than 100, and 15,09\% have between 501 and 1000. It is still interesting to relate the proportion of employees and mobile corporate devices, according to Table 1 below:

Table 1: Relationship employees $X$ mobile devices

\begin{tabular}{c|c|c}
\hline $\mathrm{N}^{\circ}$ of devices & Employees & Mobile devices \\
\hline Less than 100 & $3,77 \%$ & $11,32 \%$ \\
\hline Between 101 and 500 & $13,21 \%$ & $41,51 \%$ \\
\hline Between 501 and 1000 & $15,09 \%$ & $15,09 \%$ \\
\hline More than 1000 & $67,92 \%$ & $32,08 \%$ \\
\hline
\end{tabular}


In Table 1, the massive use of such devices, mainly in the companies with up to 500 employees, was observed. From 500 employees, there is a tendency to balance the use of devices or any other event that was not possible to identify, being possible to draw some inferences that may explain such relationships, like: the business segment and/or a type of the activity of the company like, for example, external sales.

Another aspect that can influence this relationship is the fact that it has become more and more common for the employees to use their personal devices for professional purposes, strategic known as BYOD (Bring Your Own Device), which may make the challenge of the IT managers to manage the devices and mobile applications even more expressive.

Following the mobile devices, there are the advances of the use of cloud computing resources, which refer to the shared and interconnected use of storage resources, computing capacity and processing, being able to be accessed over the internet from any place and any device.

This was the focus of motivation of question $7(\mathbf{Q 7})$, in which it was possible to verify the reality of the use of cloud computing, with $79,25 \%$ of the respondents affirming the use of cloud software and $20,75 \%$ affirming that they do not use it. This model allows the adoption of diverse types of software as a service to make the innovation process in the organizations agile.

Cloud computing allows the companies to incorporate innovations in the IT field without affording the costs of acquiring the software license and implementing a specific infrastructure (systems and hardware) to run the applications.

In the software cloud model, the costs are only related to the payment of a monthly fee that refers to the services and specific processing resources that are being used and that are hosted on the server of the service provider. However, the adoption of cloud computing technology by the companies cannot only be seen from the cost point of view, but from an expansive technology, which takes the financial and strategic aspects, architectural technology and Management into consideration (RIBEIRO; BIANCHINI, 2017).

From another aspect, virtualization of datacenters is one more technological resource that impacts the process of SAM, by considering the separation degree between software and hardware and introducing configurations for dynamic 
INDEPENDENT JOURNAL OF MANAGEMENT \& PRODUCTION (IJM\&P)

http://www.ijmp.jor.br

v. 9, n. 2, April - June 2018

ISSN: 2236-269X

DOI: 10.14807/ijmp.v9i2.730

changes, which are unquestionably more difficult to keep track of and manage, from the compliance point of view with licenses, notwithstanding the benefits of such resource for the management of datacenter.

Question 8 (Q8) sought to know the adoption degree of such technology. It was observed that 52 out of the 53 respondents, corresponding to $98,11 \%$, affirm that virtualization is proven to be a technology that has been adopted by many companies; and 1,89\% affirm that it is not. Virtualization allows using an existing server to execute two or more distinct systems, as each one runs inside its own virtual machine. Thus, expenses on new equipment are avoided and the possible software and hardware resources of the server that are idle can be used. Consequently, it delivers significant advantages in terms of IT efficiency, reduction of costs, more flexibility and infrastructure availability, contributing to the objectives of IT management.

\subsection{Sam in the Companies}

In the last questionnaire block, questions 9 to 20 researched into the real scenario and aspects of SAM, it means, in the environment of the companies through IT managers, according to the benefits and requirements of the tiers of implementation development defined in the ISO/IEC 19770 standard.

Questions 09 to 12 investigated the basic requirements established in Tier 1 Reliable Database, according to the ISO/IEC 19770-1 standard, it means, the first stage of the implementation of SAM, in which the objective is to identify hardware and software assets, through the inventory procedure.

Table 2 below was elaborated in order to make the comprehension of the results related to the process of SAM in the companies easy.

In question 9 (Q9: Is there a hardware inventory?), it was observed that $77,36 \%$ of the companies perform the hardware inventory, and in $28,30 \%$ of the companies this process is also performed in an automated way with tools that perform the search and registration of hardware in a communication network. By considering the size of the companies and the quantity of installed equipment, a more expressive use of automation tool for hardware inventory was expected. On the other hand, it was interesting to observe that $9,43 \%$ of the respondents informed that this process is not yet performed, but they suggest the intention to implement it. 
INDEPENDENT JOURNAL OF MANAGEMENT \& PRODUCTION (IJM\&P)

http://www.ijmp.jor.br

v. 9, n. 2, April - June 2018

ISSN: 2236-269X

DOI: 10.14807/ijmp.v9i2.730

Table 2: Question distribution for the processes of SAM in the companies

\begin{tabular}{|c|c|c|c|c|c|}
\hline \multirow{3}{*}{ Question } & \multicolumn{5}{|c|}{ Likert Scale } \\
\hline & 5 & 4 & 3 & 2 & 1 \\
\hline & $\begin{array}{c}\text { Yes, } \\
\text { automated }\end{array}$ & Yes & $\begin{array}{l}\text { Do not } \\
\text { know }\end{array}$ & $\begin{array}{l}\text { Not } \\
\text { yet }\end{array}$ & No \\
\hline (Q9) & $28,30 \%$ & $49,06 \%$ & $13,21 \%$ & $9,43 \%$ & $0 \%$ \\
\hline (Q10) & $16,98 \%$ & $56,60 \%$ & $11,32 \%$ & $13,21 \%$ & $1,89 \%$ \\
\hline (Q11) & $26,42 \%$ & $47,17 \%$ & $13,21 \%$ & $11,32 \%$ & $1,89 \%$ \\
\hline (Q12) & $20,75 \%$ & $50,94 \%$ & $11,32 \%$ & $16,98 \%$ & $0 \%$ \\
\hline (Q13) & $26,42 \%$ & $37,74 \%$ & $11,32 \%$ & $20,75 \%$ & $3,77 \%$ \\
\hline (Q14) & $7,55 \%$ & $52,83 \%$ & $13,21 \%$ & $11,32 \%$ & $15,09 \%$ \\
\hline (Q15) & $1,89 \%$ & $37,74 \%$ & $13,21 \%$ & $39,62 \%$ & $7,55 \%$ \\
\hline (Q16) & $9,43 \%$ & $43,40 \%$ & $15,09 \%$ & $28,30 \%$ & $3,77 \%$ \\
\hline (Q17) & $3,77 \%$ & $56,60 \%$ & $15,09 \%$ & $22,64 \%$ & $1,89 \%$ \\
\hline (Q18) & $0 \%$ & $47,17 \%$ & $13,21 \%$ & $30,19 \%$ & $9,43 \%$ \\
\hline (Q19) & $1,89 \%$ & $66,04 \%$ & $11,32 \%$ & $7,55 \%$ & $13,21 \%$ \\
\hline (Q10) & $0 \%$ & $75,47 \%$ & $11,32 \%$ & $5,66 \%$ & $7,55 \%$ \\
\hline
\end{tabular}

In question 9 (Q9: Is there a hardware inventory?), it was observed that $77,36 \%$ of the companies perform the hardware inventory, and in $28,30 \%$ of the companies this process is also performed in an automated way with tools that perform the search and registration of hardware in a communication network. By considering the size of the companies and the quantity of installed equipment, a more expressive use of automation tool for hardware inventory was expected. On the other hand, it was interesting to observe that $9,43 \%$ of the respondents informed that this process is not yet performed, but they suggest the intention to implement it.

Another relevant observation was the inexistence of a completely negative answer (Answer: No), fact that affirms the preliminary conditioning of this tool for the implementation of SAM, and even the relevance of this process in the ambit of IT management, suggesting what those that do not have inventory yet (Answer: Not yet) intend to do.

Questions 10 and 11 asked the managers about the performance of the inventory process of acquired and installed software, respectively. As to question 10 (Q10: Is there an acquired software inventory?), it was observed that $73,58 \%$ of the companies perform inventory for acquired software, however, only in $16,98 \%$ of the companies this process is performed in an automated way. In $13,21 \%$ of the companies it was possible to realize the intention to implement such process, in counterpoint, $1,89 \%$ of the managers simply informed that this process is not performed, suggesting no intention to implement it at that moment. 
INDEPENDENT JOURNAL OF MANAGEMENT \& PRODUCTION (IJM\&P)

http://www.ijmp.jor.br

v. 9, n. 2, April - June 2018

ISSN: 2236-269X

DOI: 10.14807/ijmp.v9i2.730

As to question 11 (Q11: Is there an installed software inventory?), it means, those ones effectively activated in the hardware devices in the network, and as expected, the result obtained in question11 is similar to the one in the previous question. It was observed that $73,59 \%$ of the companies perform the inventory for installed software, seeing that in $26,42 \%$ of the companies this process is performed in an automated way. In $11,32 \%$ the implementation intention can be inferred and, the same way, $1,89 \%$ of the managers simply informed the non-achievement of this process.

In addition, question 12 (Q12: Is it possible to identify how many, which and where the software assets are installed?), sought to validate if the performed inventory process allows to identify, quantify and map software assets. Consonant with the result of the questions about the performance of the inventory for hardware and software, $71,69 \%$ of the managers informed that such instrument indeed allows to identify, quantify and map their assets, accomplishing, this way, the main objective of Tier $\mathbf{1}$-having inventory knowledge so that you can manage it - according to the ISO/IEC 19770-1 standard.

Additionally, even if one of the options of the answering scale highlights the automation function of software asset management (Answer: Yes, automated), it was chosen a specific question about the use of an automation tool (software) with the objective to highlight the contribution of this resource to the process of SAM, being this the focus of question 13.

In relation to question 13 (Q13: Is software asset management performed with the use of inventory tools?), it was observed that in $64,16 \%$ of the companies, software assets management is performed with the help of some inventory tool, according to their IT managers. Moreover, $20,75 \%$ of the managers informed that they do not use it yet, but it is possible to infer the intention to use it. In this result, it is pertinent to highlight the observance of divergence with the results presented in Table IV, which indicated that the hardware and software inventories are performed in an automated way (Answer: Yes, automated) in $26 \%$ of the companies, approximately.

As to the pointed divergence, there are indeed diverse hardware and software inventory solutions in the market, from free to complex and paid solutions developed by major software manufacturers, like Microsoft and IBM, with focus on the copyright of their products. In addition, the major consulting and audit companies provide 
INDEPENDENT JOURNAL OF MANAGEMENT \& PRODUCTION (IJM\&P)

http://www.ijmp.jor.br

v. 9, n. 2, April - June 2018

ISSN: 2236-269X

DOI: 10.14807/ijmp.v9i2.730

inventory solutions aiming at offering assurance of conformity to audit cases, as well as providing an opportunity to reduce costs and optimizethe use of corporate software for their clients.

In general, such solutions sweep the whole network to identify the installed devices, searching for hardware and software information on different platforms, whether they be Windows, Linux, Mac, and storing them in a single Configuration Management Database (CMDB).

After the identification of the existing software assets by following the implementation stages defined in the ISO/IEC 19770-1 standard, it starts the stage in which occurs the effective software asset management, denominated - Tier 2 - in which it is possible to recognize not only the lack of information about software assets but also opportunities to optimize and reduce costs, allowing, therefore, the so called win-wins, it means, immediate benefits from the basic software asset management. This tier also embodies the establishment of rules, policies, responsibilities and definition of competences of SAM.

In this context, questions 14 and 15 investigated, based on the inventory, the accomplishment of the procedures for conformity analysis, as well as the existence of policies on software assets. This comparison process consists of the analyses of software contracts and copyrights according to each licensing model from the suppliers, through hardware and software inventory.

The auditory conformity and the reduction of costs are among the main benefits of SAM, however, it is primarily necessary to confront the information about acquired and installed software according to inventory data. As results of question 14 (Q14: Are any comparisons between the installed software and the acquired software performed?), this procedure is performed by $60,38 \%$ of the companies, and $7,55 \%$ of them use the specific asset discovery and inventory data software, which may speed this stage and identify potential conflicts. It is possible to realize that $11,32 \%$ of the companies informed that they do not perform comparative analysis between the acquired and installed software data yet, but the answer option (Answer: Not yet) suggests intention to accomplish it in the future. The verification of license agreement does not occur in 15,09\% of the companies, even though the preliminary inventories are performed.

It is still part of this stage to review the necessities to use software, and perform the renegotiation and license renewal processes, if it is the case. Therefore, 
INDEPENDENT JOURNAL OF MANAGEMENT \& PRODUCTION (IJM\&P)

http://www.ijmp.jor.br

v. 9, n. 2, April - June 2018

ISSN: 2236-269X

DOI: 10.14807/ijmp.v9i2.730

it is important to know the internal "owners" of the licenses, it means, who the people and department that use each software asset are.

In relation to the requirements for the development of SAM, in Tier 3, question 15 (Q15: Are there policies, rules and procedures that, allied to inventory tool, manage the lifecycle of the software assets (development/acquisition/maintenance and download)?), it was observed that only $39,63 \%$ of the companies have management instruments, such as policies, rules and/or procedures that deal with the information obtained through inventory, against $47,17 \%$ of the companies that affirmed they do not have any instruments, although $39,62 \%$ of them suggest the intention to implement these resources.

Questions 16 to 18 had the objective to verify the results reached with the implementation of SAM. The benefit of effective compliance in asset audits is reached in 52,83\% of the companies, according to question 16 (Q16: Does the current process of software asset management guarantee compliance of asset audits?), a result that expresses a successful relation regarding the objectives of SAM, if the companies that have hardware and software inventories (approximately $70 \%$ ), and still the fact that only $40 \%$ of them have defined rules and/or procedures for SAM, are considered the universe of the research.

On the other hand, $32,07 \%$ of the companies informed that the current process of SAM does not guarantee compliance of software license, suggesting fragility in the inventory and asset analyses stages, or yet, resulting from the lack of automation tools and of procedures and rules that make the process easy and agile.

In question 17 (Q17: Is the current process of software asset management applied to the optimization of software use and as a basis for the acquisition of new software assets?) allied with compliance, the research aimed at investigating the noticed results in relation to the optimization of the already acquired user licenses, as well as to the acquisition process. According to Table IV, $60,37 \%$ of the investigated IT managers confirmed that the implementation of the SAM process is performed with such objective, although the formulated question does not allow to quantify the reached economy and/or optimization. In $22,64 \%$ of the companies the SAM process is not aimed at this objective, suggesting the intention to reach it in the future, opposing $1,89 \%$ of negative manifestation of the implementation of SAM for this purpose. 
INDEPENDENT JOURNAL OF MANAGEMENT \& PRODUCTION (IJM\&P)

http://www.ijmp.jor.br

v. 9, n. 2, April - June 2018

ISSN: 2236-269X

DOI: 10.14807/ijmp.v9i2.730

The focus of question 18 (Q18: Does the current process of software asset management allow the alignment of IT investments with strategic objectives?) was to investigate the implementation of SAM, as a strategic competency that, through the alignment of IT investments, permits to contribute to the strategic objectives, according to Tier 4 of the ISO/IEC 19770 standard. In this ambit, it is interesting to highlight that there was no incidence of answer "automated process", it means, the process of analysis and investment decision-making, which allows the alignment of IT investments with the software assets, occurs in a manual way, according to data from $47,17 \%$ of the managers. It is also expressive to observe that $30,19 \%$ of the managers informed that the current process does not allow any contribution related to automation of investment, but it is suggestive that there will be future pretensions soon, against $9,43 \%$ of the managers that stated it negatively.

To complement the understanding of the scenario of SAM in the companies, questions 19 and 20 focused on the human resources inserted in the process. According to question 19 (Q19: Does your company have a team or a professional acting in software asset management?), in 67,93\% of the companies there is at least one professional aiming at SAM, and in 1,89\% of the cases it is a dedicated and specialized resource in this process. It is a positively expressive result with regard to comprehending the relevance of SAM for the IT managers, in the ambit of the governance they represent. Only $20,76 \%$ of the managers informed that there are not professionals actin in the process of SAM, since $7,55 \%$ of them suggest the intention to have one in the future.

To conclude, the last question, number 20 (Q20: Does your company have professionals with knowledge of the main licensing models from the software providers?), referred to the knowledge of licensing models from the main software manufacturers/suppliers, considering it to be a relevant aspect for the process of SAM. As the knowledge of the diverse licensing models, $75,47 \%$ of the managers informed that they have professionals with such competence, against only $13,21 \%$ of them who admitted not having any. However, this apparently positive result does not guarantee the achievement of the expected objectives with the implementation of SAM. Firstly, it is necessary to focus the existence of this competency on the effective implementation of SAM, by following its implementation and development stages. 
In relation to the implementation of SAM in the researched companies, the observed results suggest compatibility with the study performed by KPMG (2010), which pointed that $50 \%$ of the organizations in Brazil have deficiencies in the maturity SAM, once they do not have complete and precise information about software copyright, 34\% have limited control, but do not adopt procedures or tools for SAM and only $16 \%$ implemented some procedures and tools for SAM, but the derived information may not be reliable and, generally, it is not part of the decisionmaking process. It is pertinent to except that the comparison above considers that the study of this research is limited to the companies in the city of Rio de Janeiro, while the study by KPMG embodies the national ambit, justifying certain differentiation in the assessment of the development of SAM in the companies of the city of Rio de Janeiro, target of this research, with the national scenario, which contemplates companies of other diverse economic segments and sizes.

Next, the obtained results were integrated and interrelated, creating a relationship between the development tiers of the implementation of SAM and their objectives, defined in the ISO/IEC 19770-1 standard, with the questions in the third block of the questionnaire, according to Table 3 :

Table 3: Relationship between questions and stage of development of SAM

\begin{tabular}{c|c|c}
\hline Stage & Requirement & Question \\
\hline Tier 1 & Reliable data & $9,10,11$ e 12 \\
\hline Tier 2 & Keep track of assets & 13 e 14 \\
\hline Tier 3 & Efficiency improvement & 15,16 e 17 \\
\hline Tier 4 & Alignment with the strategic objectives & 18 \\
\hline
\end{tabular}

For each question, it was then observed the distribution rate that confirms the objective accomplishment of each tier, adding up the rates of the answers "Yes, automated" and "Yes", according to Table 4. In this table, the column "Tier" was created, in which it was observed that, in the majority of the companies, the process of SAM is in the initial stage of development - Tier 1, followed by Tier 2 . 
INDEPENDENT JOURNAL OF MANAGEMENT \& PRODUCTION (IJM\&P)

http://www.ijmp.jor.br

v. 9, n. 2, April - June 2018

ISSN: 2236-269X

DOI: 10.14807/ijmp.v9i2.730

Table 4: Relationship between the questions and the positive distribution

\begin{tabular}{|c|c|c|}
\hline Question & $\begin{array}{c}\text { Positive } \\
\text { distribution } \\
\text { (AnswersYESandYES, } \\
\text { AUTOMATED) }\end{array}$ & Tier \\
\hline 09 & $77,36 \%$ & \multirow{4}{*}{$\begin{array}{c}\text { Tier } \\
1\end{array}$} \\
\hline 10 & $73,58 \%$ & \\
\hline 11 & $\overline{73,59 \%}$ & \\
\hline 12 & $\overline{71,69 \%}$ & \\
\hline 13 & $64,16 \%$ & \multirow[t]{2}{*}{$\begin{array}{c}\text { Tier } \\
2\end{array}$} \\
\hline 14 & $60,38 \%$ & \\
\hline 15 & $39,63 \%$ & \multirow{3}{*}{$\begin{array}{c}\text { Tier } \\
3\end{array}$} \\
\hline 16 & $52,83 \%$ & \\
\hline 17 & $60,37 \%$ & \\
\hline 18 & $47,17 \%$ & $\begin{array}{c}\text { Tier } \\
4\end{array}$ \\
\hline
\end{tabular}

\section{CONCLUSION}

It was initially performed a literature review, especially regarding the ISO/IEC 19770-1 standard and academic works aiming at software asset management, which assisted in the creation, application and analysis of the proposed questionnaire with focus on IT management. Therefore, the answer about the scenario of the process of software asset management in large and midsize companies of Rio de Janeiro was founded in the knowledge verification of the aspects of SAM identified in the literature review and of the current situation of the process of SAM in the companies.

In relation to the situation of the implementation of SAM, the analysis of result allowed to conclude that in the majority of the companies the SAM process is still in the initial stage of development - Tier 1 - in which only the reliable data on software assets are guaranteed, followed by Tier 2. It is relevant to highlight that about $25 \%$ of the companies do not even recognize or are able to identify their software assets.

On the other hand, approximately $47 \%$ of the companies have already reached the stage Optimized - Tier 4 - in which the process of SAM is already able to contribute to the organizational strategic objectives, however it is essential to accentuate that the result was not achieved through verified and corroborated evidence, but actually based on the perception of the respondents.

Still, in relation to the scenario of SAM in the companies, it was possible to verify that the current stage of implementation allows approximately $50 \%$ of them the accomplishment of the conformity to software audits, the optimization of the use and acquisition of software licenses and even, in a little smaller incidence, allows to 
contribute to the alignment of IT investments with strategic objectives, due to the effective rationalization of control of software assets. Eventually, it was observed that as the management process develops, fewer companies fit these stages.

It is a relevant factor to consider that the implementation of a program for software asset management consumes IT budget resources, or with investment in dedicate human resources or with the acquisition of a tool for inventory automation and analysis of conformity, still varying as the processes are created and matured.

The recovery of this investment varies from a certain level of inefficiency before the implementation until the time the plain management is capable of interfering in the organizational objectives, being one of the responsibilities of IT managers to control the development level of SAM adequate to his organization, so the implementation cost is not higher than the obtained return.

As more companies incorporate the management of software assets by considering the resulting benefits - monitoring of assets, conformity, efficiency and cost reduction - as an IT strategy capable of promoting some competitive advantage for the organization, it is possible to expect an expansion tendency towards its adoption.

The objective of this research was investigating the scenario of the implementation of software asset management in companies in the city of Rio de Janeiro, and it was based on the stages of development of SAM defined in the ISO/IEC 19779-1 standard. Other researches may complement and extend the results of this work by analyzing the scenario of SAM in national ambit, or for other segments and companies sizes.

\section{REFERENCES}

ABES (2014). Manual ABES de Gestão de Ativos de Software versão 1. Available at http:// www.abessoftware.com.br. Access: 15/06/2015.

ASSOCIAÇÃO BRASILEIRA DE NORMAS TÉCNICAS (ABNT). (2012). NBR ISO/IEC 19770-1:2012 - Information technology - Software asset management Part 1: Processes. Rio de Janeiro.

ASSOCIAÇÃO BRASILEIRA DE NORMAS TÉCNICAS (ABNT) (2005). NBR ISO/IEC 27002 - Código de Prática para a Gestão de Segurança da Informação. Rio de Janeiro.

BANCO NACIONAL DE DESENVOLVIMENTO ECONÔMICO E SOCIAL (Brasil) (2010). Circular 11/2010 - Alterações das normas relativas ao porte das beneficiárias. Available at: 
http://www.bndes.gov.br/SiteBNDES/export/sites/default/bndes_pt/Galerias/Arquivos /produtos/download/Circ011_10.pdf. Access: 15/06/2015.

BOWEN, P.; CHEUNG, M.; ROHDE, F. (2007). Enhancing IT governance practices: a model and case study of organization's efforts. Accounting Information Systems, v. 8, p.191-221. DOI: 10.1016/j.accinf.2007.07.002

FERNANDES, A.; ABREU, V. (2008). Implantando a governança de TI: da estratégia à gestão de processos e serviços. 2 ed. Rio de Janeiro: Brasport.

FULGENCIO, P. C. (2007). Glossário Vade Mecum: administração pública, ciências contábeis, direito, economia, meio ambiente. São Paulo: Mauad.

HAES, S.; GREMBERGEN, W. Van (2005) IT governance structures, processes and relational mechanisms: achieving IT/business alignment in a major Belgian financial group. In: INTERNATIONAL CONFERENCE ON SYSTEM SCIENCES, 38, Hawaii. Procedings. Hawaii.

KPMG (2010). Gerenciamento de Ativos de Software. Available at: http://www.kpmg.com.br/publicacoes/Gerenciamento_Ativos_30jun.pdf. Access: 15/06/2015.

MCAFEE, A. (2004). Do you have too much IT? MIT Sloan Management Review, v. 45, n. 3, p. 18-22.

RIBEIRO, A. S.; BIANCHINI, D. (2017). The Deployment of Systems in Cloud Computing Environment: a Methodology to Select and Prioritize Projects. IEEE Latin America Transactions, v. 15, n. 3. p. 557-562. DOI: $10.1109 /$ TLA.2017.7867608.

WANG, Y. et al. (2015). The interaction effect of IT assets an IT management on firm performance: A system perspective. International Journal of Information Management, v. 35, n. 5, p. 580-593. DOI: 10.1016/j.ijinfomgt.2015.06.006. 